\title{
Strategische Planning en Fusies in Vlaamse Gemeenten
}

Een Essay over Vlaamse Ervaringen met New Public Management Hervormingen

B. George

Aanvaard voor publicatie in Bestuurskunde. Dit is de laatste auteursversie. Gelieve te citeren als:

George, B. (2019). Strategische Planning en Fusies in Vlaamse Gemeenten: Een Essay over Vlaamse Ervaringen met New Public Management Hervormingen. Bestuurskunde, Forthcoming.

In de afgelopen jaren werden Vlaamse gemeenten geconfronteerd met een stroom aan New Public Management hervormingen. De twee wellicht meest opvallende hervormingen betreffen de introductie van een strategisch planningssysteem genaamd de Beleids- en Beheerscyclus (BBC) alsook het voorzien van financiële stimuli voor gemeenten die fuseren. Beide hervormingen zijn niet uniek aan de Vlaamse context en komen overgewaaid uit Nederland waar een vergelijkbaar strategisch planningssysteem - het Beleids- en Beheerinstrumentarium (BBI) - reeds in de jaren '80 werd geïntroduceerd en gemeentelijke fusies al decennialang op de politieke agenda staan. In dit essay wordt kritisch naar deze Vlaamse hervormingen gekeken met als voornaamste vraag: Op welke publieke waarden focussen deze hervormingen, en wat betekent dit voor de Vlaamse en Nederlandse lokale publieke sector? Dit essay gebruikt New Public Governance principes zoals strategisch denken en de lerende organisatie om deze vraag te beantwoorden.

In the past years, Flemish municipalities have been confronted with a plethora of New Public Management reforms. The two probably most salient reforms include the introduction of a strategic planning system titled the Policy and Management Cycle (PMC) as well as the provision of financial stimuli for municipalities that undertake a merger. Both reforms are not unique to the Flemish context. Indeed, similar reforms took place in the Netherlands, where the Policy and Management Instruments (PMI) - a 
strategic planning system - were introduced in the 80 s and municipal mergers have been part of the political agenda for several decades. But also in, for instance, the United Kingdom (i.e. the Best Value Regime in 1999) as well as Denmark (i.e. the municipal mergers in 2007) similar reforms took place. In this essay, these Flemish reforms are critically evaluated, taking into account following question: Which public values are triggered through these reforms, and what might this imply for the Flemish and Dutch local public sector? This essay uses New Public Governance principles such as strategic thinking and the learning organization to answer this question.

Keywords: New Public Management, Local Government, Strategic Planning, Municipal Mergers, Flemish Municipalities. 


\section{Inleiding}

De bestuurskunde als wetenschap wordt gedomineerd door drie theoretische lenzen. Allereerst is er de traditionele lens, ook wel de Weberiaanse Bureaucratie genoemd. Deze lens stelt dat de overheid in de eerste plaats de rechtstaat dient te bewaken, een gelijke behandeling moet geven aan elke burger en gekenmerkt moet worden door een neutrale administratie. De tweede lens, New Public Management, bekijkt de overheid meer als een bedrijf en stelt dat de overheid voornamelijk effectief en efficiënt moet zijn door gebruik te maken van praktijken komende uit het bedrijfsleven. De derde lens, New Public Governance, stelt dat de overheid meer moet focussen op het aanpakken van de "grote" maatschappelijke uitdagingen van vandaag door samen te werken met andere actoren in een netwerk en burgers te stimuleren om met de overheid te co-creëren en co-produceren (Osborne, 2006). Elke lens focust met andere woorden op andere publieke waarden: Rechtvaardigheid, gelijkheid en neutraliteit (Weberiaanse Bureaucratie), effectiviteit, efficiëntie en verantwoording (New Public Management), samenwerking, responsiviteit en sociale impact (New Public Governance). Het is belangrijk om te melden dat deze drie lenzen niet "los" van elkaar bestaan - in elke publieke organisatie of andere entiteit is elke lens in meer of mindere mate aanwezig. Publiek managers en beleidsmakers moeten dus een balans vinden tussen al deze publieke waarden en beseffen dat elke lens voor- en nadelen heeft die zorgvuldig moeten worden afgewogen (Koppenjan, 2012). Een interessant voorbeeld van hoe deze drie lenzen naast elkaar bestaan betreft het burgerkabinet in Gent. Dit was een initiatief om de Gentenaar meer te betrekken bij beleidsvorming in Gent - wat mooi past binnen New Public Governance denken. Echter, in de praktijk bleek het kabinet weinig effectief vanwege een vrij magere opkomst en bleken slechts een select aantal bevolkingsgroepen te participeren, wat gelijkheidsprincipes aantastte.

In de praktijk zien we dat voornamelijk New Public Management hervormingen op de agenda staan in de meeste OESO-landen. Ook in Vlaanderen is dit het geval. Zo dragen de twee wellicht meest prominente hervormingen in Vlaamse gemeenten een duidelijke New Public Management bril: Enerzijds 
is er de aandacht en financiële stimuli voor gemeenten die fuseren (de achterliggende logica is de theorie rond schaaleconomieën). Anderzijds is er de verplichte adoptie van een strategisch planningssysteem met een focus op meerjarenplannen, doelen, actieplannen, indicatoren en streefwaarden (de achterliggende logica hier is de synoptische planningstheorie en de doelbepalingstheorie).

Deze hervormingen werden uiteraard niet geïnitieerd vanuit verkeerde intenties, er heerst een resoluut geloof bij verschillende actoren binnen de Vlaamse Overheid dat fusies en strategische planning zullen bijdragen aan de capaciteit van Vlaamse gemeenten. Hier zit een bron van waarheid in. Strategische planning kan, althans wanneer "goed" geïmplementeerd, een krachtig mechanisme zijn om strategisch denken te stimuleren (Bryson, 2018). Ook schaalgrootte kan mogelijks helpen, grotere gemeenten kunnen aantrekkelijker zijn om in te werken, wat sterkere profielen aantrekt, en hebben een betere positie in onderhandelingen met hoger gelegen overheden alsook partners uit de private, publieke en non-profit sector (Reingewertz, 2012). Tegelijkertijd worden bovenstaande "voordelen" vaak niet ondersteund door empirisch bewijs. Fusies van lokale besturen in Denemarken hebben bijvoorbeeld bitter weinig bijgedragen aan de financiële capaciteit van deze besturen en creëerden zelfs een democratisch deficit burgers voelden zich meer vervreemd van het grotere lokale bestuur, de overheid stond verder van burgers af en was minder responsief ten opzichte van hun wensen (e.g. Blom-Hansen et al., 2016; Lassen \& Serritzlew, 2011). Ook strategisch planning wordt fel bekritiseerd en blijkt vaak niet meer te zijn dan heel klassieke "rationele" planningsvormen. De focus ligt op weinig ambitieus prestatiemanagement en schuld-vermijdend gedrag zonder echt na te denken welke belangrijke maatschappelijke uitkomsten men wilt realiseren, welke capaciteit daarvoor nodig is en hoe men continue kan blijven open staan voor nieuwe opduikende strategieën die aandacht vereisen (e.g. Bovaird, 2008; George et al., 2017).

Het doel van dit essay is dan ook om deze twee Vlaamse hervormingen van naderbij te bekijken gericht op het identificeren van de "volgende" stappen. Hoe kunnen Vlaamse gemeenten verder evolueren en bouwen op de capaciteit die ze nu hebben? Om dit doel te realiseren licht ik eerst de twee 
hervormingen nader toe. Vervolgens beargumenteer ik wat de volgende stap kan zijn op basis van New Public Governance concepten en ik concludeer met de implicaties van dit essay voor de Vlaamse en Nederlandse lokale publieke sector.

\section{Strategische Planning in Vlaamse Gemeenten}

Alle Vlaamse gemeenten moeten sinds het fiscale jaar 2014 een meerjarenplan formuleren als onderdeel van een Beleids- en Beheercyclus (BBC). Dit meerjarenplan beslaat de beleidscyclus 2014-2019 en kan jaarlijks worden aangepast. In het meerjarenplan worden prioritaire beleidsdoelstellingen geformuleerd, inclusief de bijhorende actieplannen, indicatoren, streefwaarden en benodigde financiën. Deze prioritaire beleidsdoelstellingen vormen een belangrijk management- en beleidsinstrument voor het college van burgemeester en schepenen aangezien de vooruitgang ten opzichte van deze doelen moet worden

teruggekoppeld naar de gemeenteraad. Ook dient elke gemeente jaarlijks, als onderdeel van de jaarrekening, te evalueren hoe ze heeft gepresteerd ten opzichte van deze doelen. Dit biedt wederom sturing aan de Vlaamse Overheid, die zo kan opvolgen hoe gemeenten presteren ten opzichte van hun eerder geformuleerde beleidsdoelen. Ook voor de nieuwe beleidscyclus 2020-2025 dient een meerjarenplan te worden geformuleerd.

Deze verplichting komt voort uit twee vaststellingen: Enerzijds was er voor deze hervorming vaak veel planlast aanwezig in Vlaamse gemeenten, voor bijna elk beleidsdomein had de gemeente een apart plan nodig - het meerjarenplan komt hieraan tegemoet omdat het de bedoeling is dat alle domeinen in dit ene plan worden geïntegreerd. Anderzijds was deze hervorming een reactie op de precaire financiële situatie van sommige Vlaamse gemeenten. Een expliciet onderdeel van het meerjarenplan is dan ook om aan te tonen hoe men binnen een aantal jaren naar een financieel gezonde toestand kan evolueren (te bewijzen via een positief "autofinancieringsmarge", een financiële ratio die de solvabiliteit van een gemeente weergeeft). Het is belangrijk om op te merken dat de Vlaamse Overheid duidelijk is over de verplichting om een meerjarenplan te hebben, inclusief prioritaire beleidsdoelstellingen. Echter, hoe dit 
meerjarenplan kan worden geformuleerd en geïmplementeerd alsook wat de inhoud en vorm van beleidsdoelen kan zijn blijft eerder ambigue. Er kan dan ook veel variatie gevonden worden op basis van institutionele, organisatorische en omgevingskenmerken van een gemeente. ${ }^{1}$

\section{Gemeentelijke Fusies in Vlaanderen}

Een tweede hervorming die prominent op de agenda staat van de Vlaamse Overheid betreft gemeentelijke fusies. Het is belangrijk om op te merken dat de aandacht voor gemeentelijke fusies niet noodzakelijk "nieuw" is in Vlaanderen. Reeds in de jaren '70 vonden grootschalige fusies plaats van gemeenten over gans België (dus niet enkel in Vlaanderen). Sinds die tijd is het aantal Vlaamse gemeenten echter stabiel gebleven - met uitzondering van een fusie van Stad Antwerpen met enkele randgemeenten - en pas in januari 2019 vonden nieuwe fusies plaats, weliswaar op een relatief beperkte schaal (15 Vlaamse gemeenten fuseren tot 7 fusiegemeenten). Deze recente fusies zijn het gevolg van Vlaams beleid, de Vlaamse Overheid stimuleert immers vrijwillige fusies tussen gemeenten door middel van o.a. een fusiebonus (een schuldovername van 500 euro per inwoner). De achterliggende rationale is dat grotere besturen ook een grotere "bestuurskracht" genieten. Ze hebben voldoende capaciteit om in te spelen op en om te gaan met de uitdagingen waarmee lokale besturen vandaag (en in de toekomst) worden geconfronteerd.

Het Vlaams beleid omtrent gemeentelijk fusies is vrijwillig van aard, de Vlaamse Overheid wenst dus gemeenten te stimuleren om te fuseren maar legt dit alsnog niet dwingend op. Bovendien is het belangrijk om op te merken dat de stimuleringsinitiatieven van de Vlaamse Overheid gericht waren op gemeenten die op 1 januari 2019 wensten te fuseren. De vraag blijft of deze initiatieven geldig zullen blijven in de komende beleidscyclus of mogelijks vervangen zullen worden door andere maatregelen. Immers, ondanks de vrij gunstige initiatieven valt het toch op dat slechts een beperkt aantal gemeenten meegaan in de Vlaamse agenda. Bovendien volgen er in mei 2019 verkiezingen (Vlaams, federaal en Europees), fusies zullen ongetwijfeld wederom onderdeel worden van politieke programma's. Er is met 
andere woorden een grote onzekerheid over wat het beleid aangaande gemeentelijke fusies zal worden van de volgende Vlaamse regering. ${ }^{2}$

\section{Lessen voor Vlaamse en Nederlandse Lokale Besturen}

Bovenstaande hervormingen tonen een duidelijke link met het New Public Management gedachtegoed van de jaren '80. In een interview gepubliceerd in het tijdschrift Binnenband (2017) stelt Liesbeth Homans (Vlaams Minister van Binnenlands Bestuur) letterlijk dat "[d]e Vlaamse Regering wil inzetten op een efficiëntere overheid". ${ }^{3}$ Uiteraard is hier op zich niets mis mee, en is efficiëntie een belangrijke publieke waarde om na te streven. De uitgangssituatie van Vlaamse gemeenten in 2013 was immers financieel precair. Vanwege een toch eerder bureaucratische manier van gemeentelijke organisatie hadden heel wat Vlaamse gemeenten financiële problemen, planlast en - in het algemeen - weinig transparante instrumenten die gebruikt konden worden als verantwoordingsmechanismen. De animo voor beide hervormingen blijft echter beperkt, zo is de BBC weinig populair bij lokale politici (George, 2016) en hebben slechts een heel beperkt aantal gemeenten een fusie ondergaan. Bovendien is het belangrijk om de vraag te stellen of een efficiëntere overheid volstaat om een antwoord te bieden op de sociale uitdagingen van vandaag - denk bijvoorbeeld aan de duurzame ontwikkelingsdoelstellingen van de Verenigde Naties en de steeds mondiger wordende burger. Uitdagingen met betrekking tot het klimaat, migratie, terrorisme, ongelijkheid, burgerparticipatie etc. zullen niet enkel aangepakt worden door een efficiëntere overheid, maar vereisen een strategische denkende overheid en een lerende overheid - ook op het lokale niveau.

\section{Van strategisch plannen naar strategisch denken}

Wanneer strategische planning "goed" wordt uitgevoerd, kan het een instrument zijn om organisaties en andere entiteiten strategisch te laten denken. Strategisch denken betekent dat een publieke organisatie focust op het realiseren van duurzame publieke waarde en belangrijke maatschappelijke doelen 
(outcomes), met aandacht voor het systeem waarin ze zich bevindt en de afhankelijkheid van andere entiteiten binnen dat systeem (systems thinking), en dat ze haar strategieprocessen voldoende aanpast aan haar eigen context en noden (processes). Vanwege de focus op outcomes, systems thinking en gecontextualiseerde processes past strategisch denken dus mooi in het gedachtegoed van New Public Governance en is het primordiaal om te vermijden dat een publieke organisatie enkel denkt aan output, de eigen interne organisatie en gebruik maakt van standaard "off the shelf" strategieprocessen uit de private sector. Echter, in de praktijk blijkt vaak dat strategische planning wordt gereduceerd tot een financiële oefening resulterend in een reeks van weinig ambitieuze doelstellingen. Dit wordt wellicht gedreven door een schrik voor latere afrekeningen indien doelstellingen niet worden behaald. Ook in sommige Vlaamse gemeenten is dit zichtbaar. Zo blijkt uit vorig onderzoek dat sommige Vlaamse gemeenten op een informele manier het meerjarenplan formuleren - zonder een gedegen analyse van de interne en externe omgeving. Bovendien gebeurt dit in sommige gevallen ook op een exclusieve wijze - de financieel directeur speelt een centrale rol maar er is weinig participatie van leden van de gemeenteraad, dienstverlenende medewerkers, burgers en andere externe stakeholders (George, 2017). Bij dergelijke gemeenten resulteert dit in weinig ambitieuze doelstellingen, die niet gekoppeld zijn aan het mandaat, de waarden en de missie van de gemeente noch enige bijdrage leveren aan het bereiken van een ambitieuze visie voor de gemeente. Deze praktijk is weinig strategisch. De essentie van strategie is dat organisaties en andere entiteiten enerzijds ambitieuze aspiraties kunnen formuleren en anderzijds ook de capaciteit kunnen ontwikkelen om deze te implementeren. Om ervoor te zorgen dat strategisch planning dus resulteert in strategisch denken zijn volgende condities van belang (Bryson, 2018; George, 2016; George, 2017; George et al., 2016; George et al., 2018a):

- De actoren verantwoordelijk voor de opmaak van het strategisch plan beschikken over de nodige analytische en creatieve capaciteit alsook kennis van de gemeente en haar burgers, van de 
gemeentelijke organisatie en van de bestuursakkoorden komend uit de lokale politiek. Hiervoor is doordacht georganiseerde stakeholderparticipatie doorheen het planningsproces belangrijk.

- Voorafgaand aan de opmaak van het strategisch plan wordt vastgesteld wat het mandaat is van de gemeente, alsook wat haar missie en waarden zijn.

- Op basis van dit mandaat, de missie en waarden, wordt vervolgens een analyse gevoerd met betrekking tot de interne en externe omgeving van de gemeente. Het belangrijkste is dat deze analyse eindigt met de voornaamste strategische issues.

- Dit zijn fundamentele uitdagingen van de gemeente die ervoor zorgen dat ze haar mandaat, missie en waarden niet kan behalen. Deze issues vormen de strategische agenda van de gemeente en worden op continue wijze gemonitord doorheen de beleidscyclus.

- De strategische issues worden vertaald in concrete strategieën. Het belangrijkste hierbij is om meerdere opties te genereren voor het aanpakken van een issue en na te denken over mogelijke belemmeringen om deze optie te realiseren. Hierdoor ontstaat een beter beeld over de complexiteit van een issue alsook welke optie realistisch is en hoe deze gerealiseerd kan worden.

- Op basis hiervan wordt vervolgens een doordachte selectie van opties gemaakt die de eigenlijke strategieën zijn van de gemeente - hiermee gaat de gemeente haar issues aanpakken.

- Eens de gemeente haar strategieën heeft geselecteerd start het implementeren. Een haalbare, inspirerende en wenselijke visie wordt geformuleerd - het toekomstbeeld van de gemeente indien ze inderdaad haar strategische issues succesvol aanpakt en haar missie realiseert. Deze visie moet burgers, medewerkers, politici stimuleren om te werken aan de realisatie van het plan.

- Het implementeren van het plan impliceert een noodzaak aan "hardere" management-praktijken (e.g, financieel management, prestatiemanagement, netwerk management) en "zachtere" management-praktijken (e.g. verandermanagement, personeels-management, netwerk governance) zowel in de gemeentelijke organisatie alsook in haar netwerk. 
- Ook leren van en met andere organisaties en entiteiten is belangrijk tijdens het implementeren van het plan. Strategie is immers niet statisch maar dynamisch. Dit punt wordt in wat volgt verder toegelicht.

Ten slotte is het belangrijk op te merken dat bovenstaande lijst niet beschouwd mag worden als een standaardformule. Elke strategische benadering dient aangepast te worden aan de context en het is essentieel dat publieke organisaties bewust strategieprocessen configureren naar de voor hun meest relevante vorm. Ook dit is immers een belangrijk aspect van strategisch denken.

\section{Van fusies naar lerende organisaties}

De aandachtige lezer heeft wellicht opgemerkt dat in bovenstaande succesfactoren niet wordt gesproken over doelstellingen, indicatoren en streefwaarden. Deze instrumenten zijn immers geen noodzakelijk onderdeel van strategische planning (Bryson, 2018), ondanks dat beleidsdoelstellingen centraal staan in de Vlaamse hervorming. Doelstellingen, indicatoren en streefwaarden zijn instrumenten die horen bij prestatiemanagement - een mogelijke en eerder "harde" benadering voor het implementeren van strategische plannen. De Beleids- en Beheercyclus in Vlaamse gemeenten is dus eigenlijk geen strategische planning maar eerder een vorm van prestatiemanagement.

Uit een recente meta-analyse blijkt dat prestatiemanagement in publieke organisaties gemiddeld een beperkte positieve impact heeft (Gerrish, 2016). De achterliggende reden is dat het hebben van doelen, indicatoren en streefwaarden niet noodzakelijk betekent dat deze instrumenten daadwerkelijk gebruikt worden voor fundamenteel leren. Uit onderzoek in Vlaanderen blijkt bijvoorbeeld dat indicatoren kunnen resultaten in schuld-vermijdend gedrag door lokale politici. In de plaats van de vraag te stellen waarom er slecht wordt gescoord op sommige indicatoren (en er dus mogelijks nieuwe strategieën noodzakelijk zijn), wordt gerommeld aan de financiering van publieke diensten (George et al., 2016). Ook blijkt dat prestatiemanagement enkel wordt gebruikt door Vlaamse lokale politici om 
fundamenteel te leren wanneer deze binnen een bredere institutionele context wordt geplaatst (George et al., 2018b). Het louter hebben van doelen, indicatoren en streefwaarden is dus onvoldoende. Een lerende overheid gebruikt informatie van deze tools alsook andere informatie uit haar interne en externe omgeving om op een continue wijze te reflecteren op de adequaatheid van de gekozen strategieën alsook de relevantie van mogelijke opduikende strategieën. Voor een lerende overheid is strategie dus dynamisch en geen statisch plan dat 5 jaar onveranderd blijft. Zo'n lerende overheid bevat 7 componenten (OECD, 2018):

- $\quad$ Er is een gedeelde visie die focust op alle burgers in de gemeente en breed gedragen wordt binnen de gemeentelijke organisatie alsook door de stakeholders van de gemeente.

- Er zijn continue leeropportuniteiten voor medewerkers van de gemeentelijke organisatie die zichzelf willen bijscholen en professioneel willen ontwikkelen.

- Team leren en samenwerking tussen medewerkers van de gemeentelijke organisatie wordt actief gestimuleerd.

- De gemeentelijke organisatie heeft een cultuur gericht op onderzoek, innovatie en verkenning. Er is ruimte voor te experimenten en hiervan bij te leren.

- Er zijn formele systemen aanwezig om de uitwisseling van kennis te stimuleren tussen medewerkers van de gemeentelijke organisatie alsook tussen de gemeente en haar stakeholders.

- Er wordt samen met de externe omgeving van de gemeentelijke organisatie geleerd, bijvoorbeeld via co-creatie en co-productie; inclusief hoger gelegen overheden en andere gemeenten.

- Leiders in de gemeentelijke organisatie stimuleren en faciliteren leren binnen hun teams, en geven teamleden hier ook alle opportuniteiten voor.

Wanneer we bovenstaande kenmerken bekijken, dwingt volgende vraag zich op: In welke mate dragen gemeentelijke fusies bij aan deze nieuwe organisatievorm? Het antwoord hierop is onzeker. Het staat wel 
vast de lerende organisatie niet noodzakelijk makkelijker te bereiken is in grotere gemeenten. Bovendien wordt grotere gemeenten vaak een gebrek aan responsiviteit verweten - de afstand tussen de gemeente en de burger wordt immers ook groter. Is de focus van de Vlaamse Overheid op gemeentelijke fusies dus gerechtvaardigd? Vanuit efficiëntie en New Public Management denken wellicht wel, maar wanneer we kijken naar belangrijke waarden binnen New Public Governance zijn fusies ontoereikend. De adoptie van de lerende organisatie kan hieraan tegemoet komen.

\section{Conclusies}

In dit essay worden twee recente New Public Management hervormingen in Vlaamse gemeenten geïntroduceerd en geanalyseerd vanuit een New Public Governance lens. Deze hervormingen - zijnde de introductie van een strategisch planningssysteem en het stimuleren van gemeentelijke fusies - zijn niet uniek aan Vlaanderen en staan wereldwijd op de beleidsagenda. Echter, beide hervormingen focussen sterk op waarden als effectiviteit, efficiëntie en verantwoording. Een gevaar bestaat dat meer governancegerelateerde waarden zoals samenwerking, responsiviteit en sociale impact onderbelicht blijven. Om dit te vermijden is het belangrijk dat lokale besturen strategisch denken, wat betekent dat ze ambitieuze aspiraties kunnen uitwerken alsook de capaciteit kunnen ontwikkelen om deze aspiraties te bereiken (sociale impact). Ook het implementeren van een lerende organisatie kan helpen om ervoor te zorgen dat lokale besturen tijdig nieuwe uitdagingen in de interne en externe omgeving kunnen detecteren en een gepast antwoord kunnen bedenken (responsiviteit). Ten slotte betekent strategisch denken en de lerende organisatie ook samenwerking met partners, enerzijds om samen ambitieuze strategieën te realiseren en anderzijds om samen continue van en met elkaar te leren (samenwerking). Uiteraard betekent dit niet dat strategische planning en fusies niet zullen werken in Vlaamse gemeenten, het betekent echter wel dat in hun huidige vorm - beide hervormingen onvoldoende aandacht besteden aan een breed spectrum aan publieke waarden. En net die aandacht is de essentie van goed bestuur. Ook voor Nederland schuilt hier een belangrijke les. De sterke focus op beleidsdoelstellingen in Nederlandse gemeenten en de bijhorende 
rekenkamerevaluaties met betrekking tot doelmatigheid kunnen leiden tot een rigide strategisch planningssysteem zoals in sommige Vlaamse gemeenten - ook hier gaat het niet enkel over het behalen van beleidsdoelen, maar het genereren van sociale impact. En ook fusies blijven aandacht krijgen in Nederlandse lokale besturen - weliswaar niet altijd in dezelfde vorm (bv. ambtelijke fusie i.p.v. gemeentelijke fusie), maar de logica is dezelfde (efficiëntie-winst). Net als in Vlaanderen mag dit niet de enige reden zijn waarom fusies worden ondernomen en dient er ten minste ook zorgvuldig nagedacht te worden over andere vormen van gemeentelijke organisatie gericht op leren en samenwerking.

\section{Eindnoten}

${ }^{1}$ Zie ook: https://www.vlaanderen.be/nl/gemeenten-en-provincies/dienstverlening-van-gemeenten-enprovincies/de-beleids-en-beheerscyclus-voor-lokale-besturen.

${ }^{2}$ Zie ook: https://lokaalbestuur.vlaanderen.be/strategische-projecten/fusie.

${ }^{3}$ Bron: https://lokaalbestuur.vlaanderen.be/sites/default/files/public/publicaties/binnenband fusies.pdf (geconsulteerd op 02-02-2019).

\section{Literatuur}

Blom-Hansen, J., Houlberg, K., Serritzlew, S., \& Treisman, D. (2016). Jurisdiction size and local government policy expenditure: Assessing the effect of municipal amalgamation. American Political Science Review, 110, 812-831.

Bovaird, T. (2008). Emergent strategic management and planning mechanisms in complex adaptive systems: the case of the UK Best Value initiative. Public Management Review, 10, 319-340.

Bryson, J. M. (2018). Strategic planning for public and nonprofit organizations: A guide to strengthening and sustaining organizational achievement. New York: John Wiley \& Sons.

George, B. (2016). Unravelling the determinants of strategic planning effectiveness in public organizations: a strategic decision-making perspective at the individual and organizational level. Ghent: Ghent University, Faculty of Economics and Business Administration. 
George, B. (2017). Does strategic planning 'work'in public organizations? Insights from Flemish municipalities. Public Money \& Management, 37, 527-530.

George, B., Baekgaard, M., Decramer, A., Audenaert, M., \& Goeminne, S. (2018b). Institutional isomorphism, negativity bias and performance information use by politicians: A survey experiment. Public Administration, Early view DOI: 10.1111/padm.12390.

George, B., Desmidt, S., \& De Moyer, J. (2016). Strategic decision quality in Flemish municipalities. Public Money \& Management, 36, 317-324.

George, B., Desmidt, S., Cools, E., \& Prinzie, A. (2018a). Cognitive styles, user acceptance and commitment to strategic plans in public organizations: an empirical analysis. Public Management Review, 20, 340-359.

George, B., Desmidt, S., Nielsen, P. A., \& Baekgaard, M. (2017). Rational planning and politicians' preferences for spending and reform: replication and extension of a survey experiment. Public Management Review, 19, 1251-1271.

Gerrish, E. (2016). The impact of performance management on performance in public organizations: A meta-analysis. Public Administration Review, 76, 48-66.

Koppenjan, J. (2012). The New Public Governance in public service delivery: Reconciling efficiency and quality. The Hague: Eleven International Publishing.

Lassen, D. D., \& Serritzlew, S. (2011). Jurisdiction size and local democracy: Evidence on internal political efficacy from large-scale municipal reform. American Political Science Review, 105, 238-258.

OECD. (2018). Developing Schools as Learning Organisations in Wales. Paris: OECD Publishing.

Osborne, S. P. (2006). The New Public Governance? Public Management Review, 8, 377-387.

Reingewertz, Y. (2012). Do municipal amalgamations work? Evidence from municipalities in Israel. Journal of Urban Economics, 72, 240-251.

\section{Titulatuur}


B. George (PhD), Erasmus Universiteit Rotterdam, Universitair Docent Publiek Management, E: george@essb.eur.nl,W: https://bertgeorge.com. 